\title{
Association between Perceived Parenting Style and Adolescents' Attitudes toward Suicide
}

\author{
Seo-Hyun Choi ${ }^{1}$, Sang-Eun Lee ${ }^{2,3}$, Chai Won Lee ${ }^{2,3}$, Seri Maeng ${ }^{1}$, Jisung Son ${ }^{1}$, \\ Won-Hyoung Kim¹, Jae Nam Bae', Jeong Seop Lee ${ }^{1}$, and Hyeyoung Kim ${ }^{1,4}$ \\ ${ }^{1}$ Department of Psychiatry, Inha University Hospital, Incheon, Korea \\ ${ }^{2}$ Incheon Jung-gu Community Mental Health Center, Incheon, Korea \\ ${ }^{3}$ Department of Nursing, Inha University College of Medicine, Incheon, Korea \\ ${ }^{4}$ Department of Psychiatry, Seoul National University College of Medicine, Seoul, Korea
}

\begin{abstract}
Objectives: Adolescent suicide, a major cause of adolescent death, is affected by various factors, including attitudes toward suicide. This study investigated the association between parenting style and adolescents' attitudes toward suicide and the mediating role of attitude toward suicide between parenting style and suicidal ideation.

Methods: We surveyed 1,071 adolescents from eight middle schools in Incheon, Korea. The survey included sociodemographic information, attitudes toward suicide, perception of parenting style, depression severity, and suicidality.

Results: Students in the authoritarian parenting group had a more permissive attitude toward suicide compared with the democratic and permissive parenting groups. These students considered that suicide is justified in certain situations and that choosing suicide is an individual's right. They also had a negative attitude toward talking about suicide or intervening in others' suicide. This association remained statistically significant after adjusting for the impact of confounding factors that could affect attitudes toward suicide, except for suicidal processes and preparedness to prevent suicide. In the mediation analysis, we observed that some factors of the attitudes toward suicide mediated between authoritarian parenting attitudes and suicidal ideation, namely, suicide as a right, preventability, suicide as normal/common, preparedness to prevent suicide, and resignation.
\end{abstract}

Conclusion: This study revealed the significant impact of parenting style on children's attitudes toward suicide. Educating parents about the appropriate parenting attitudes-sympathetic and rational-can help prevent youth suicide.

Key Words: Suicidal ideation; Parenting; Adolescents; Attitude.

Received: August 10, 2020 / Revision: September 9, 2020 / Accepted: September 14, 2020

Address for correspondence: Hyeyoung Kim, Department of Psychiatry, Inha University Hospital, 27 Inhang-ro, Jung-gu, Incheon 22332, Korea

Tel: +82-32-890-2582, Fax: +82-32-890-3536, E-mail: kimhy.md@gmail.com

\section{INTRODUCTION}

According to the World Health Organization 2016 statistical reports, suicide is the second leading cause of death in individuals between the ages of 10 and 24 years worldwide [1]. In the USA, adolescent and young adult suicide rates have been increasing since 2000; the suicide rate was 14.46 per 100,000 people in 2017 [2]. Korea’s suicide rate, although declining, remains the highest among the Organization for Economic Cooperation and Development countries; in 2009, it was at 33.8 per 100,000 people, whereas the latest data show a rate of 26.6 per 100,000 people [3-5]. According to the 2018 Korea National Statistical Office report, the most common cause of youth deaths is intentional self-inflicted death (suicide), which accounts for $36 \%$ of all deaths [5]. This rate is more than twice

This is an Open Access article distributed under the terms of the Creative Commons Attribution Non-Commercial License (https://creativecommons.org/licenses/by-nc/4.0) which permits unrestricted non-commercial use, distribution, and reproduction in any medium, provided the original work is properly cited. as high as that of traffic accidents (14.0\%), the second most common cause of death [5].

Suicide rates are decreasing among other age groups but increasing among adolescents, and as such, appropriate interventions are needed [3]. Suicide risk factors among adolescents include depression, maladjustment at school, impulsivity, abuse, family relationship problems, friendship problems, internet addiction, insomnia, and drinking [6,7]. Studies have reported that adolescents' attitudes toward suicide affect their suicidal behavior [8].

At the individual level of analysis, studies have shown a positive association between the two: Individuals with any kind of suicidal behavior have more tolerant and understanding attitudes toward suicide [9]. This relation was confirmed by a 25-year longitudinal study in New Zealand with a birth cohort of more than 1,000 children [10]. A study of attitudes toward suicide in 423 Slovenian teens also found that permissive attitudes are positively associated with the majority of 
suicide risk factors [9], suggesting that permissive attitudes toward suicide are more likely to be a risk factor for suicidal behavior. Factors that can influence attitudes toward suicide include family type, gender, religion, and socioeconomic status (SES).

Adolescents undergo major transformations in their propensity to evaluate and understand intricate situations and aspire to become autonomous and unique individuals [11]. The relationship between parents and children is among the most prominent factors affecting the social interactions, attachment, moral reasoning, education, and problematic behaviors of adolescents [12,13]. Indeed, parenting affects the mental health of adolescents. Therefore, parenting styles can be expected to affect adolescents' suicidal behaviors and attitudes toward suicide. A study of Hong Kong teenagers revealed that negative parenting styles are associated with suicidal behaviors [14]. Hong Kong adolescents who considered their parents' upbringing style to be authoritarian were reported to have more suicidal ideations and attempts compared with those who considered their parents' upbringing as democratic. Other studies have established that when adolescents describe their parents as showing the requisite care and affection, the risk of suicide is alleviated, whereas when parents are recognized as watchful or authoritarian, the risk of suicide increases significantly [14-17]. A study of 604 Portuguese adolescents showed that parenting style affects the formation of secure attachment and confirmed the mediating role of parental attachment in the association between parenting style and suicidal ideation [18]. However, research on the relevance of parenting style to adolescents' attitudes toward suicide is lacking.

Thus, we hypothesized that if adolescents perceive their parents' attitudes negatively, they may have a more accepting and understandable attitude toward suicide. Additionally, we analyzed whether attitudes toward suicide can be a mediator of the effects of parenting attitude on suicidal behavior.

\section{METHODS}

\section{Participants}

All middle schools located in Jung-gu District, Incheon, participated in the study, and all eighth-grade students from one of eight middle schools were enrolled. Of the 1,357 participants, 286 who did not reliably complete the survey were excluded, resulting in a final sample of 1,071 participants. When comparing the included $(n=1,071)$ and excluded $(n=$ 286) students, we observed statistically significant differences in sex, suicidal ideation, and depression severity (Supplementary Table 1 in the online-only Data Supplement). In the excluded group, the proportion of girls, percentage of students who ever had suicidal ideation, and mean depression scores were lower compared with the included group. No statistically significant differences were noted between the two groups in other variables, such as the number of family members, religion, SES, suicide plans, and suicide attempts.

\section{Procedure}

We asked the students to complete a questionnaire that contained items on their attitude toward suicide and parenting after their homeroom teacher provided an explanation of the study during class. The Institutional Review Board of Inha University Hospital (registration number 2018-06-032) approved the study protocol and waiving of informed consent.

\section{Measurement}

We gathered basic demographic information, such as gender, family type, religion, and SES, along with details on family psychiatric history, suicide ideation, suicide plans, and suicide attempts. The participants were asked to rank their family's economic condition compared with others. The participants' suicidality was assessed by the suicidality subscale of the Korean Version of the Composite International Diagnostic Interview (K-CIDI version 2.1): "Have you ever seriously thought about committing suicide?" "Have you ever made a plan to commit suicide?" and "Have you ever attempted suicide?"

\section{Attitudes Towards Suicide scale}

The attitudes towards suicide (ATTS) scale was developed by Renberg and Jacobsson to assess attitudes toward suicide [19]. Kodaka et al. [20], in their study on suicide assessment, recommended the ATTS scale as the most available and relevant tool. We used a Korean version of the ATTS with 37 items on attitudes toward suicide [21]. Answers were rated on a five-point Likert scale: $1=\mathrm{I}$ strongly disagree, $2=\mathrm{I}$ do not agree, $3=$ I cannot decide, 4=I agree, and 5=I strongly agree. We adopted the 10-factor model suggested by Renberg and Jacobsson that included 34 ATTS items after excluding three items with low factor loadings or low communality. The ten factors were as follows: suicide as a right, incomprehensibility of suicide, non-communication, preventability of suicide, tabooing, suicide as normal/common, suicide as a process, relation-caused preparedness to prevent suicide, and suicide as a solution or resignation (Supplementary Table 2 in the online-only Data Supplement) [19].

\section{Parental Authority Questionnaire}

The Parental Authority Questionnaire, developed by Buri [22] based on Baumrind's parenting attitude theory, consists of three sub-metrics of self-reporting measures for youth respondents: permissive, authoritarian, and democratic. We used 
the translated and validated Korean version of this scale and classified the attitudes into the three groups according to the present study results [23]. Permissive parenting is when parents have with little control over their children's behavior and allows the latter to do as they wish. Authoritarian parenting is when parents strictly control their children's behavior in their desired direction. Democratic parenting is a warm, reasonable, and consistent way for parents to guide their children [22].

\section{Center for Epidemiologic Studies Depression \\ Scale-Revised (CESD-R)}

The Center for Epidemiologic Studies Depression Scale (CESD) was developed by Radloff [24] in 1977 to assess depression. It was revised in 2004 to assess depressive symptoms consistent with the DSM-IV [25]. In 2016, Lee et al. [26] assessed the psychometric properties of the Korean version and validated it.

\section{Statistical analysis}

All data were analyzed using SPSS 19.0 (IBM Corp., Armonk,
NY, USA). Chi-squared tests were conducted to assess the differences in demographic factors by parenting attitude group. We conducted one-way analyses of variance and post-hoc analyses to analyze the depression score and attitudes toward suicide, depending on the parenting attitude perceived by teenagers.

The severity of depression has a significant effect on attitudes toward suicide [9]. Moreover, economic status, family type, gender, and religion also affect attitudes toward suicide [8]. Thus, we used these factors as confounders in the analysis of covariance to control for their effects. To determine whether attitudes toward suicide mediate between parenting attitudes and suicidal ideation, we performed a series of regression analyses as mediation analysis, as suggested by Baron and Kenny [6].

\section{RESULTS}

\section{Sociodemographic characteristics}

Table 1 shows the participants' sociodemographic charac-

Table 1. Demographic and clinical characteristics of the pro-democracy, authoritarian, and permissive groups

\begin{tabular}{|c|c|c|c|c|c|c|}
\hline Characteristic, n (\%) & $\begin{array}{l}\text { Pro-democracy } \\
\qquad(n=776)\end{array}$ & $\begin{array}{l}\text { Authoritarian } \\
\qquad(n=177)\end{array}$ & $\begin{array}{l}\text { Permissive } \\
(\mathrm{n}=118)\end{array}$ & $\begin{array}{c}\text { Total } \\
(n=1071)\end{array}$ & p-value & Post-hoc \\
\hline Sex & & & & & 0.623 & \\
\hline Male & $383(49.4)$ & $82(46.3)$ & $59(50.0)$ & $524(48.9)$ & & \\
\hline Female & $393(50.6)$ & $95(53.6)$ & $59(50.0)$ & $547(51.1)$ & & \\
\hline Number of family & & & & & 0.971 & \\
\hline$\leq 3$ & $144(18.6)$ & $32(18.2)$ & $20(17.0)$ & $196(18.3)$ & & \\
\hline 4 & $407(52.5)$ & $91(50.9)$ & $59(50.0)$ & $557(52.0)$ & & \\
\hline $5 \geq$ & $225(28.9)$ & $54(30.5)$ & $39(33.0)$ & $318(29.6)$ & & \\
\hline Religion & & & & & 0.980 & \\
\hline Yes & $322(41.5)$ & $75(42.4)$ & $49(41.5)$ & $446(41.6)$ & & \\
\hline No & $454(58.5)$ & $102(57.6)$ & $69(58.5)$ & $625(58.4)$ & & \\
\hline Socioeconomic status & & & & & $<0.001$ & $* \pitchfork$ \\
\hline High & 341 (43.9) & $52(29.4)$ & $37(31.4)$ & $430(40.2)$ & & \\
\hline Middle & 301 (38.8) & $65(36.7)$ & $53(44.9)$ & $419(39.1)$ & & \\
\hline Low & $134(17.3)$ & $60(33.9)$ & $28(23.7)$ & $222(20.7)$ & & \\
\hline Suicide idea & & & & & $<0.001$ & $* \pitchfork$ \\
\hline Absent & $602(77.6)$ & $83(46.9)$ & $80(67.8)$ & $765(71.4)$ & & \\
\hline Present & $174(22.4)$ & $94(53.1)$ & $38(32.2)$ & $306(28.6)$ & & \\
\hline Suicidal plan & & & & & $<0.001$ & $* \ddagger$ \\
\hline Absent & 720 (92.8) & $141(79.7)$ & $103(87.3)$ & $964(90.0)$ & & \\
\hline Present & $56(7.2)$ & $36(20.3)$ & $15(12.7)$ & 107 (10.0) & & \\
\hline Suicidal attempt & & & & & $<0.001$ & $* \dagger$ \\
\hline Absent & $736(94.8)$ & $147(83.0)$ & $105(89.0)$ & 988 (92.2) & & \\
\hline Present & $40(5.2)$ & $30(17.0)$ & $13(11.00)$ & $83(7.8)$ & & \\
\hline K-CESD-R, mean (SD) & $8.21(12.29)$ & $19.10(18.80)$ & $12.44(15.08)$ & $10.47(14.46)$ & 0.001 & $* \dagger$ \\
\hline
\end{tabular}

*the mean difference between the pro-democracy and authoritarian groups is statistically significant $(p<0.05)$, ${ }^{\dagger}$ the mean difference between the pro-democracy and permissive groups is statistically significant $(p<0.05)$, "the mean difference between the authoritarian and permissive groups is statistically significant $(p<0.05)$. K-CESD-R: Korean-Center for Epidemiologic Studies Depression Scale-Revised 
teristics. The sample consisted of $49.4 \%$ boys and $50.6 \%$ girls. Their mean K-CESD-R score was 10.47 points (SD 14.46). Among the participants, $72.5 \%, 16.5 \%$, and $11.0 \%$ considered their parents' attitudes as democratic, authoritarian, and permissive, respectively. We observed no significant differences in gender, number of family members, or religion by parenting attitude. However, differences in the depression scores between the groups were statistically significant. In the authoritarian parenting group, the mean depression score was the highest, and the proportion of students who had thought of, planned, and attempted suicide was also the highest. The highest percentage of respondents in the democratic group reported having a higher SES, whereas the highest percentage of respondents in the other groups had a middle SES.

\section{Comparison of attitudes toward suicide among adolescents raised under the three parenting styles}

We performed a one-way analysis of variance and a post hoc analysis for each factor of attitudes toward suicide. Table 2 shows the mean scores of attitudes toward suicide among the three parenting groups. Statistically significant differences were found in the mean values of the three parenting groups for all the factors of attitudes toward suicide.

Compared with their peers with democratic and permissive parents, students who felt that their parents' parenting style was authoritarian scored high for suicide as a right, noncommunication, tabooing, suicide as normal/common, suicidal process, suicide as relationship-caused, and resignation, and low in incomprehensibility of, preventability of, and preparedness to prevent suicide. Thus, students in this group considered suicide as a reasonable choice and regarded it as an individual's right. Additionally, they were reluctant to talk about suicide or intervene in others' suicide. They also found it difficult to prevent others from planning suicide. The percentage of respondents who were ready to prevent others from dying by suicide was also lower than that of the other groups.

Table 2. Comparison of the adolescents' attitudes toward suicide among three parenting styles

\begin{tabular}{|c|c|c|c|c|c|}
\hline Factor & $\begin{array}{c}\text { Pro-democracy } \\
\quad(\text { mean } \pm S D)\end{array}$ & $\begin{array}{l}\text { Authoritarian } \\
\text { (mean } \pm S D)\end{array}$ & $\begin{array}{l}\text { Permissive } \\
(\text { mean } \pm S D)\end{array}$ & p-value & Post-hoc \\
\hline Suicide as a right & $2.95 \pm 0.61$ & $3.30 \pm 0.67$ & $3.12 \pm 0.53$ & $<0.001$ & $* \dagger$ \\
\hline Incomprehensibility & $3.34 \pm 0.88$ & $2.85 \pm 0.94$ & $3.03 \pm 0.88$ & $<0.001$ & $* \dagger$ \\
\hline Non-communication & $3.22 \pm 0.49$ & $3.38 \pm 0.61$ & $3.28 \pm 0.48$ & 0.001 & $*$ \\
\hline Preventability & $4.07 \pm 0.68$ & $3.58 \pm 0.79$ & $3.88 \pm 0.73$ & $<0.001$ & $* \pitchfork$ \\
\hline Tabooing & $2.56 \pm 0.63$ & $2.80 \pm 0.79$ & $2.71 \pm 0.68$ & $<0.001$ & $*$ \\
\hline Normal-common & $2.99 \pm 0.79$ & $3.46 \pm 0.78$ & $3.19 \pm 0.76$ & $<0.001$ & $* \dagger$ \\
\hline Suicidal process & $3.03 \pm 0.83$ & $3.27 \pm 0.86$ & $3.18 \pm 0.77$ & 0.002 & $*$ \\
\hline Relation caused & $2.59 \pm 0.71$ & $2.87 \pm 0.79$ & $2.63 \pm 0.69$ & $<0.001$ & $*$ \\
\hline Preparedness to prevent & $3.80 \pm 0.78$ & $3.51 \pm 0.86$ & $3.64 \pm 0.79$ & $<0.001$ & $*$ \\
\hline Resignation & $1.83 \pm 1.00$ & $2.31 \pm 1.18$ & $3.88 \pm 1.06$ & $<0.001$ & $* \dagger$ \\
\hline
\end{tabular}

*the mean difference between the pro-democracy and authoritarian groups is statistically significant ( $\mathrm{p}<0.05$ ), ${ }^{\dagger}+\mathrm{the}$ mean difference between the pro-democracy and permissive groups is statistically significant $(p<0.05)$, *the mean difference between the authoritarian and permissive groups is statistically significant $(p<0.05)$

Table 3. Comparison of the adolescents' attitudes toward suicide among three parenting styles after adjusting confounders*

\begin{tabular}{|c|c|c|c|c|c|}
\hline Factor & $\begin{array}{c}\text { Pro-democracy } \\
(\text { mean } \pm S D)\end{array}$ & $\begin{array}{l}\text { Authoritarian } \\
(\text { mean } \pm S D)\end{array}$ & $\begin{array}{l}\text { Permissive } \\
(\text { mean } \pm S D)\end{array}$ & p-value & Post-hoc \\
\hline Suicide as a right & $2.99 \pm 0.02$ & $3.18 \pm 0.05$ & $3.10 \pm 0.06$ & $<0.001$ & $\dagger$ \\
\hline Incomprehensibility & $3.29 \pm 0.03$ & $3.08 \pm 0.06$ & $3.09 \pm 0.08$ & 0.003 & $\dagger$ \\
\hline Non-communication & $3.23 \pm 0.02$ & $3.38 \pm 0.04$ & $3.28 \pm 0.05$ & 0.002 & $\dagger$ \\
\hline Preventability & $4.03 \pm 0.02$ & $3.74 \pm 0.05$ & $3.91 \pm 0.06$ & $<0.001$ & †§ \\
\hline Tabooing & $2.57 \pm 0.02$ & $2.78 \pm 0.05$ & $2.71 \pm 0.06$ & 0.002 & $\dagger$ \\
\hline Normal-common & $3.03 \pm 0.03$ & $3.31 \pm 0.06$ & $3.15 \pm 0.07$ & $<0.001$ & $\dagger$ \\
\hline Suicidal process & $3.07 \pm 0.03$ & $3.15 \pm 0.06$ & $3.15 \pm 0.07$ & 0.360 & \\
\hline Relation caused & $2.59 \pm 0.03$ & $2.87 \pm 0.06$ & $2.64 \pm 0.07$ & $<0.001$ & $\dagger$ \\
\hline Preparedness to prevent & $3.76 \pm 0.03$ & $3.65 \pm 0.06$ & $3.68 \pm 0.07$ & 0.163 & \\
\hline Resignation & $1.88 \pm 0.04$ & $2.13 \pm 0.08$ & $2.08 \pm 0.09$ & 0.004 & $\dagger$ \\
\hline
\end{tabular}

*confounders: CESD-R score, sex, religion, socio-economic status, family numbers, ${ }^{\dagger}$ the mean difference between the pro-democracy and authoritarian groups is statistically significant $(\mathrm{p}<0.05)$, "the mean difference between the pro-democracy and permissive groups is statistically significant $(p<0.05)$, sthe mean difference between the authoritarian and permissive groups is statistically significant $(p<0.05)$ 
Meanwhile, students in the democratic parenting group expressed that suicide was difficult to understand and prevent, but that they were willing to prevent others from dying by suicide. Additionally, they viewed the claim that suicide is acceptable in certain situations.

To adjust for the influence of factors that reportedly affect attitudes toward suicide, including depression, gender SES, and religion, we included these factors as confounders and analyzed them using analysis of covariance (Table 3). Differences in the mean of most factors of attitudes toward suicide remained statistically significant between the democratic and authoritarian groups, except for suicidal processes and preparedness to prevent suicide. The permissive group differed significantly from the democratic group only in the incomprehensibility factor, and from the authoritarian group only in the preventability factor. We found no statistically significant differences in other factors between the groups.

\section{Mediation analyses}

To test the mediation effect of attitudes toward suicide on the association between parenting attitude and suicidal ideation, we conducted a first regression on the influence of par-

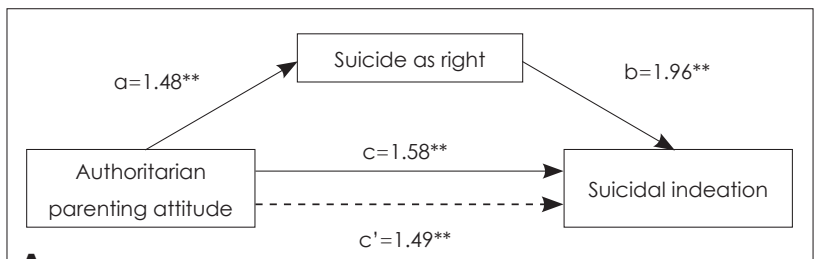

A
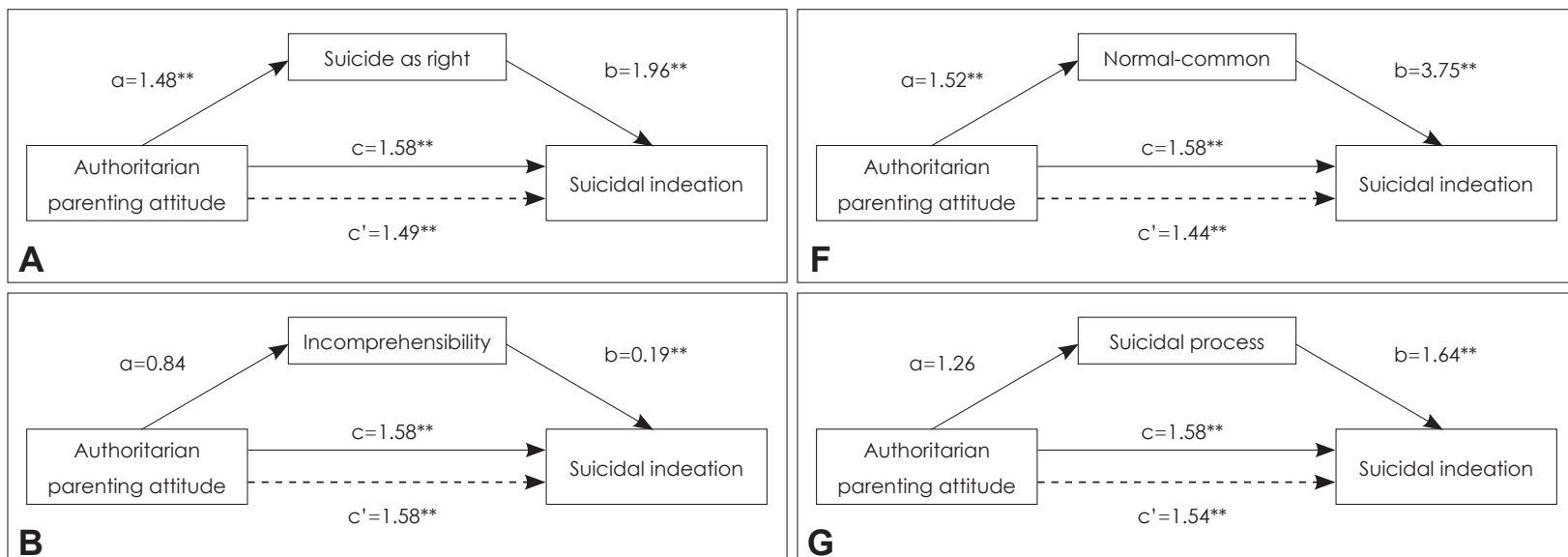

\section{$\mathbf{F}$}
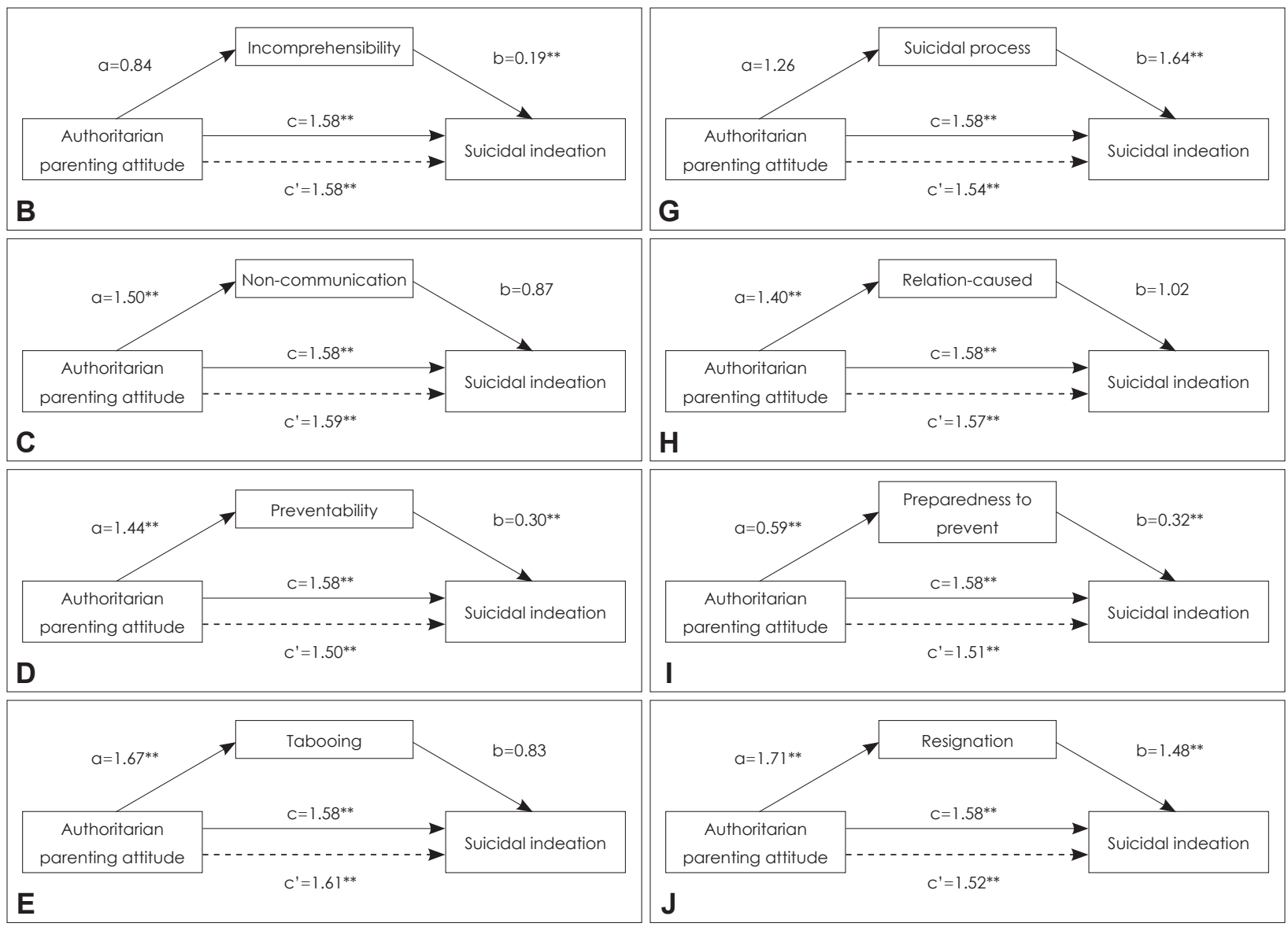

Fig. 1. Mediation model of authoritarian parenting attitude, attitudes towards suicide, and suicidal ideation. A through J in figure shows the results of a mediated analysis of 10 factors of attitude toward suicide. A: suicide as a right, B: incomprehensibility, C: non-communication, D: preventability, E: tabooing, F: normal-common, G: suicidal process, H: relation-caused, I: preparedness to prevent, J: resignation. Logistic regression coefficient are as follows: $\operatorname{Exp}(B)=a \times$ authoritarian parenting attitude, for the association of authoritarian parenting attitude with factor of attitude toward suicide; $\operatorname{Exp}(B)=b \times$ factor of attitude toward suicide, for the association of factor of attitude toward suicide with suicide ideation; $\operatorname{Exp}(B)=C \times$ authoritarian parenting attitude, for total effect (association of pro-democracy score with suicide ideation); $\operatorname{Exp}(B)=C^{\prime} \times$ authoritarian parenting attitude for direct effect (association of authoritarian parenting attitude with suicide ideation). ${ }^{*} \mathrm{p}<0.05,{ }^{* *} \mathrm{p}<0.01$. 
enting attitude on suicidal ideation, followed by a second regression on the influence of parenting attitude on attitudes toward suicide. A third regression examined attitudes toward suicide and suicidal ideation. Results of the mediation analysis showed that some factors of attitudes toward suicide mediated between authoritarian parenting attitudes and suicidal ideation. The mediating factors included suicide as a right, preventability of suicide, suicide as normal/common, preparedness to prevent suicide, and resignation.

Fig. 1 shows a model of the mediated analysis of parenting style, attitudes toward suicide, and suicidal ideation. Fig. 1A displays the results of the mediation analysis of the factor of suicide as a right. When the factor of suicide as a right was evaluated as a mediator, it showed a positive relation with authoritarian parenting attitude $\left(\beta_{1 \mathrm{a}}=1.48, \mathrm{p}<0.001\right)$ and suicidal ideation $\left(\beta_{1 b}=1.96, p<0.001\right)$. When suicide as a right was introduced into the model, the effect of authoritarian parenting attitude on suicidal ideation decreased (from $\beta_{1 \mathrm{c}}=1.58, \mathrm{p}<$ 0.001 to $\left.\beta_{1 c}=1.49, \mathrm{p}<0.001\right)$. Therefore, suicide as a right showed a partial mediation effect on the path of authoritarian parenting attitude and suicidal ideation. Suicide as normal/common and resignation also had a positive relation with authoritarian parenting and suicidal ideation. Preventability of and preparedness to prevent suicide had a negative relation with authoritarian parenting. When these factors-suicide as a right, preventability of suicide, suicide as normal/common, preparedness to prevent suicide, and resignation-were introduced to the model, the effect of authoritarian parenting on suicidal ideation decreased. Therefore, these factors showed a partial mediation effect on the path of authoritarian parenting and suicidal ideation. The other factors were not statistically significant, namely, incomprehensibility of suicide, noncommunication, tabooing, suicide as a process, and suicide as relationship-caused.

\section{DISCUSSION}

The present study examined the associations between the perceived parenting style and attitudes toward suicide among adolescents through a survey of 1,071 middle school students in Incheon, Korea. We found that the students in the authoritarian parenting group had a more accepting attitude toward suicide and considered suicide as difficult to prevent compared with their peers in the democratic and permissive parenting groups. We also found that some factors of attitudes toward suicide could act as mediators between parenting attitudes and suicidal ideation, including suicide as a right, preventability of suicide, suicide as normal/common, preparedness to prevent suicide, and resignation.

We divided respondents into groups according to their per- ception of their parents' parenting attitudes. The association between parenting style and suicidal ideation observed in our study is consistent with that in previous research. The risk of suicide is reportedly higher among students who perceived their parents' parenting attitude as strict, strongly controlling, and unsympathetic $[14,17]$. In our study, $53.11 \%$ of the students in the authoritarian group reported that they had thought seriously about suicide more than once compared with $28.57 \%$ in the total sample. This trend was also observed in terms of suicide plans and attempts.

Adolescents who perceived their parents' parenting style as authoritarian had more permissive attitudes toward suicide. If adolescents considered their parents as extremely strict, completely uninterested in them, unsympathetic, or irrational, they tended to consider suicide as acceptable, common, and difficult to prevent. Even when the effects of covariates were corrected, the associations between most factors of attitudes toward suicide and parenting style were statistically significant, but not for the attitudes of suicide resulting from impulsive behavior and being prepared to prevent suicide. We also noted statistically significant differences between the democratic group and authoritarian group in most factors of attitudes toward suicide, and only few significant differences with the permissive group. This difference may be because the democratic and permissive groups were not strictly divided, as reported in previous studies, given that Korean teenagers tend to perceive the permissive attitude of allowing them to do whatever they wanted as democratic [23]. Notably, the adolescents in the authoritarian and permissive parenting groups also showed few differences in their attitudes toward suicide. Studies that analyzed the impact of parental attitudes on adolescent mental health and suicidal behavior have showed that the difference between authoritarian and permissive styles is not significant [17,27], which is in line with our results, although these previous works did not clearly state the reasons for their results. Further study is needed on the possible effects of authoritarian parenting versus permissive parenting on adolescents.

Several studies have shown how parenting style affects adolescents' suicidal ideation. One study reported that parenting style affects the formation of attachment for adolescents, and that attachment with parents affects suicidal ideation. Adolescents with insecure attachments tend to solve their problems negatively or aggressively [18]. Among previous studies investigating the impact of parenting style on adolescents' mental health, Rey [27] found that controlling parenting is accompanied by a high level of depressive symptomatology. Self-determination theory suggests that parenting that supports autonomy and is characterized by high involvement and structure is accompanied by more positive psycho- 
social results [28]. Some studies have shown that children's acceptance and recognition of problems change depending on their parents' attitudes. Additionally, parenting style affects the development of children's moral reasoning. If parents tend to empathize emotionally and have a warm parenting attitude, then their children tend to have higher moral reasoning levels and show prosocial moral reasoning and prosocial behavior [29]. These tendencies may also affect children's attitudes toward suicide. In an overly strict or unsympathetic home environment, teenagers may struggle to express their thoughts or the difficulties they face and feel it unnecessary to intervene in other people's situations. Further, because they tend to choose more aggressive ways to solve problems, they can have a more accommodating attitude toward suicide and a passive attitude toward preventing others from dying by suicide.

Further analysis showed that some factors of attitudes toward suicide acted as mediators between parenting attitudes and suicidal ideation. The attitudes that could serve as mediators included an accepting attitude toward suicide, universalization of suicide, suicide as preventable, and taboo in talking about suicide. As discussed above, under strict, unsympathetic, and authoritarian parenting attitudes, adolescents may form an accepting attitude toward suicide, a reluctance to talk about suicide, and an attitude that suicide cannot be prevented. Adolescents who have an accepting attitude toward suicide have a higher risk of choosing suicide as a solution to their problems. Having an attitude that suicide cannot be prevented and reluctance to talk about it can discourage adolescents from talking to others or seeking help when they intend to die by suicide. Therefore, educating parents and adolescents to develop an accurate perception of suicide is essential in preventing suicide. Parenting attitudes should also be included in parents' education. Additionally, if teenagers are in a negative parenting environment, careful observation and active intervention for their suicidal behavior are needed.

This study is the first to analyze the association between parenting attitudes and attitudes toward suicide in the adolescent population and to explore how this association affects suicidal ideation. Although there has been one study on the association between adult attitudes toward suicide and parents' parenting attitudes, the sample size was small and only included students at a medical school in Japan [30], and the impact of this association on suicidal ideation was not examined. Our study has the advantage of a larger sample size and advanced investigation of the mediating effects of ATTS between parenting style and suicidal ideation.

The present study has several limitations. First, we evaluated parenting without classifying the main caregivers as mothers or fathers. In parenting attitudes, results may differ depend- ing on whether it concerns the father or mother. Future studies should investigate and analyze the parenting attitudes of both parents individually, which can help provide the necessary education for each parent. Second, parenting attitudes were evaluated as perceived by teenagers. However, the reliability of this assessment is not diminished compared with a questionnaire evaluating parenting behavior [23]. Third, the generalizability of our findings is limited because the study included only eighth-graders in a particular region. Nonetheless, our findings are consistent with previous studies in showing that authoritarian parenting attitudes and permissive attitudes toward suicide increase the risk of suicide $[8,14]$. Therefore, although cultural effects should be considered, the results are meaningful in that they confirm the association between parenting style and attitude toward suicide and that this association affects suicidal ideation. Finally, suicidal behavior was assessed by self-report questions, not through direct clinical interviews, and as dichotomous variables. The questions to assess suicidal ideation, suicide plans, or suicide attempts over a lifetime might be broad, as a person's risk for suicide is dynamic and changes over time. Future studies should conduct a more detailed evaluation of suicidal behaviors.

In conclusion, the parenting style perceived by adolescents significantly influenced their attitudes toward suicide, which affected their suicidal ideation. Therefore, educating parents on sympathetic, democratic, and rational parenting attitudes can help reduce the adolescent suicide rate.

\section{Supplementary Materials}

The online-only Data Supplement is available with this article at https://doi.org/10.5765/jkacap.200032.

\section{Acknowledgments}

We would like to thank the adolescents whose participation made this study possible.

\section{Conflicts of Interest}

The authors have no potential conflicts of interest to disclose.

\section{Author Contributions}

Conceptualization: Seo-Hyun Choi, Won-Hyoung Kim, Hyeyoung Kim. Data curation: all authors. Investigation: all authors. Project administration: Sang-Eun Lee, Chai Won Lee, Hyeyoung Kim. Supervision: Jeong Seop Lee, Hyeyoung Kim. Validation: Won-Hyoung Kim, Jae-Nam Bae, Hyeyoung Kim. Writing_original draft: Seo-Hyun Choi. Writing—review \& editing: Hyeyoung Kim.

\section{ORCID iDs}

$\begin{array}{ll}\text { Seo-Hyun Choi } & \text { https://orcid.org/0000-0002-2726-5610 } \\ \text { Sang-Eun Lee } & \text { https://orcid.org/0000-0003-3459-1446 } \\ \text { Chai Won Lee } & \text { https://orcid.org/0000-0002-9744-9028 } \\ \text { Seri Maeng } & \text { https://orcid.org/0000-0001-6850-5548 } \\ \text { Jisung Son } & \text { https://orcid.org/0000-0002-3218-6829 } \\ \text { Won-Hyoung Kim } & \text { https://orcid.org/0000-0002-6650-3685 }\end{array}$


Jae-Nam Bae Jeong Seop Lee https://orcid.org/0000-0002-5024-6231 Hyeyoung Kim https://orcid.org/0000-0001-5585-0334 https://orcid.org/0000-0002-2313-8892

\section{REFERENCES}

1) World Health Organization. Global Health Observatory (GHO) data [cited 2018 Jun 10]. Available from URL: https://www.who. int/gho/mortality_burden_disease/causes_death/top_10/en/.

2) AFSP. Suicide statistics [cited 2018 Jun 10]. Available from URL: https://afsp.org/about-suicide/suicide-statistics/.

3) Jeon HJ, Bae J, Woo JM. Recent statistics and risk factors of suicide in children and adolescents. J Korean Med Assoc 2013;56:9399.

4) OECD. Suicide rates [cited 2019 Sep 24]. Available from URL: https://ata.oecd.org/healthstat/suicide-rates.htm.

5) KOSIS. 2018 Korea cause of death statistics [cited 2019 Sep 24]. Available from URL: http://kosis.kr/statHtml/statHtml.do?orgId=1 01\&tblId=DT_1B34E01\&conn_path=I2.

6) Baron RM, Kenny DA. The moderator-mediator variable distinction in social psychological research: conceptual, strategic, and statistical considerations. J Pers Soc Psychol 1986;51:1173-1182.

7) Borowsky IW, Ireland M, Resnick MD. Adolescent suicide attempts: risks and protectors. Pediatrics 2001;107:485-493.

8) Stein D, Brom D, Elizur A, Witztum E. The association between attitudes toward suicide and suicidal ideation in adolescents. Acta Psychiatr Scand 1998;97:195-201.

9) Arnautovska U, Grad OT. Attitudes toward suicide in the adolescent population. Crisis 2010;31:22-29.

10) Beautrais AL, John Horwood L, Fergusson DM. Knowledge and attitudes about suicide in 25-year-olds. Aust N Z J Psychiatry 2004; 38:260-265.

11) Shikha Kapur. Adolescence: the stage of transition. Horizons of Holistic Education 2015;2:233-250.

12) Baumrind D. Current patterns of parental authority. Dev Psychol 1971:4:1-103

13) Hair EC, Jager J, Garrett SB. Helping teens develop healthy social skills and relationships: what the research shows about navigating adolescence. Washington, DC: Child Trends;2002.

14) Lai KW, McBride-Chang $C$. Suicidal ideation, parenting style, and family climate among Hong Kong adolescents. Int J Psychol 2001; 36:81-87.

15) Fergusson DM, Woodward LJ, Horwood LJ. Risk factors and life processes associated with the onset of suicidal behaviour during adolescence and early adulthood. Psychol Med 2000;30:23-39.

16) Gau SS, Chen YY, Tsai FJ, Lee MB, Chiu YN, Soong WT, et al. Risk factors for suicide in Taiwanese college students. J Am Coll Health $2008 ; 57: 135-142$
17) Donath C, Graessel E, Baier D, Bleich S, Hillemacher T. Is parenting style a predictor of suicide attempts in a representative sample of adolescents? BMC Pediatr 2014;14:113.

18) Nunes F, Mota CP. Parenting styles and suicidal ideation in adolescents: mediating effect of attachment. J Child Fam Stud 2017;26:734747.

19) Renberg ES, Jacobsson L. Development of a questionnaire on attitudes towards suicide (ATTS) and its application in a Swedish population. Suicide Life Threat Behav 2003;33:52-64.

20) Kodaka M, Postuvan V, Inagaki M, Yamada M. A systematic review of scales that measure attitudes toward suicide. Int J Soc Psychiatry 2011;57:338-361.

21) Seoul National University College of Medicine; Seoul National University Hospita; Korea Suicide Prevention Center. 2013 national survey on suicide [cited 2019 Spe 24]. Available from URL: http://www.mohw.go.kr/react/jb/sjb030301vw.jsp?PAR_MENU_ ID $=03 \& M E N U \_I D=032901 \& C O N T \_S E Q=338662$.

22) Buri JR. Parental authority questionnaire. J Pers Assess 1991;57: 110-119.

23) Lee HJ, Kang MH. The validation of the PAQ and the relationship with parenting style and family function. Stud Korean Youth 2008; 19:5-31.

24) Radloff LS. The CES-D scale: a self-report depression scale for research in the general population. Appl Psychol Meas 1977;1:385401.

25) Eaton WW, Smith C, Ybarra M, Muntaner C, Tien A. Center for Epidemiologic Studies Depression Scale: review and revision (CESD and CESD-R). In: Maruish ME, editor. The use of psychological testing for treatment planning and outcomes assessment: instruments for adults. Mahwah, NJ: Lawrence Erlbaum Associates Publishers;2004. p.363-377.

26) Lee S, Oh ST, Ryu SY, Jun JY, Lee K, Lee E, et al. Validation of the Korean version of Center for Epidemiologic Studies Depression Scale-Revised (K-CESD-R). Korean J Psychosomatic Med 2016; 24:83-93.

27) Rey JM. Perceptions of poor maternal care are associated with adolescent depression. J Affect Disord 1995;34:95-100.

28) Heaven PCL, Newbury K, Mak A. The impact of adolescent and parental characteristics on adolescent levels of delinquency and depression. Pers Individ Dif 2004;36:173-185.

29) Carlo G, Mestre MV, Samper P, Tur A, Armenta BE. The longitudinal relations among dimensions of parenting styles, sympathy, prosocial moral reasoning, and prosocial behaviors. Int J Behav Dev 2011;35:116-124.

30) Hashimoto K, Sugawara N, Tanaka O, Nakamura K, Yasui-Furukori $\mathrm{N}$. Parental bonding and attitudes toward suicide among medical college students in Japan. Neuropsychiatr Dis Treat 2014;10: 2015-2020. 
Supplementary Table 1. Demographic characteristics of excluded participants who did no reliably complete the survey

\begin{tabular}{|c|c|c|c|}
\hline Characteristic, n (\%) & Included $(n=1071)$ & Excluded $(n=286)$ & p-value \\
\hline Sex & & & $<0.001$ \\
\hline Male & $524(48.9)$ & $194(67.7)$ & \\
\hline Female & $547(51.1)$ & $92(32.3)$ & \\
\hline Number of family & & & 0.07 \\
\hline$\leq 3$ & $196(18.3)$ & $44(15.5)$ & \\
\hline 4 & $557(52.0)$ & $165(57.5)$ & \\
\hline$\geq 5$ & $318(29.6)$ & $77(27.0)$ & \\
\hline Religion & & & 0.53 \\
\hline Yes & $446(41.6)$ & $113(39.4)$ & \\
\hline No & $625(58.3)$ & $173(60.6)$ & \\
\hline Socioeconomic status & & & 0.052 \\
\hline High & $430(40.2)$ & $91(31.8)$ & \\
\hline Middle & $419(39.1)$ & $165(57.5)$ & \\
\hline Low & $222(20.7)$ & $30(10.6)$ & \\
\hline Suicide idea & & & 0.02 \\
\hline Absent & $765(71.4)$ & $227(79.2)$ & \\
\hline Present & $306(28.6)$ & $59(20.8)$ & \\
\hline Suicidal plan & & & 0.12 \\
\hline Absent & $964(90.0)$ & $267(93.4)$ & \\
\hline Present & $107(10.0)$ & $19(6.6)$ & \\
\hline Suicidal attempt & & & 0.42 \\
\hline Absent & $988(92.2)$ & $268(93.8)$ & \\
\hline Present & $83(7.8)$ & $18(6.2)$ & \\
\hline K-CESD-R, mean (SD) & $10.47(14.46)$ & $6.23(12.69)$ & $<0.001$ \\
\hline
\end{tabular}

K-CESD-R: Korean-Center for Epidemiologic Studies Depression Scale-Revised 
Supplementary Table 2. Ten factors of attitudes toward suicide and items for each factor

\begin{tabular}{|c|c|}
\hline Factor & Item \\
\hline \multirow[t]{6}{*}{ Suicide as a right } & Get help to commit suicide if severe, incurable disease—myself \\
\hline & Give help to commit suicide if severe, incurable disease-people \\
\hline & Suicide understandable if severe, incurable disease_people \\
\hline & Consider suicide if severe, incurable disease—myself \\
\hline & Suicide acceptable means to end incurable disease-people \\
\hline & Right to commit suicide-people \\
\hline \multirow[t]{4}{*}{ Incomprehensibility } & Suicide can never be justified \\
\hline & Suicides among younger people particularly puzzling \\
\hline & Suicide among the worst thing to do to relatives \\
\hline & Not understandable that people can take their lives \\
\hline \multirow[t]{5}{*}{ Non-communication } & Communication not serious \\
\hline & People who make threats seldom complete suicide \\
\hline & Suicide happens without warning \\
\hline & Relatives have no idea about what is going on \\
\hline & Most people avoid talking about suicide \\
\hline \multirow[t]{3}{*}{ Preventability } & Can always help \\
\hline & Suicide can be prevented \\
\hline & Suicide decision can't be reversed \\
\hline \multirow[t]{3}{*}{ Tabooing } & Should or would rather not talk about suicide \\
\hline & Risk to evoke suicidal thought if asked about \\
\hline & Suicide one's own business \\
\hline \multirow[t]{3}{*}{ Normal-common } & Could express suicide wish without meaning it—myself \\
\hline & Everyone has considered suicide \\
\hline & Anybody can commit suicide \\
\hline \multirow[t]{2}{*}{ Suicidal process } & Suicide considered for a long time \\
\hline & Attempts are impulsive actions \\
\hline \multirow[t]{2}{*}{ Relation-caused } & Attempts due to interpersonal conflicts \\
\hline & Attempts due to revenge and punishment \\
\hline \multirow[t]{2}{*}{ Preparedness to prevent } & Prepared to help a suicidal person-myself \\
\hline & Duty to restrain a suicidal act \\
\hline Resignation & Situations where suicide is the only solution \\
\hline
\end{tabular}

